\title{
Somatostatin and prostate cancer: role of somatostatin receptors in the control of tumor growth
}

\author{
Marica Arvigo ${ }^{1}$ \\ Massimiliano Ruscica ${ }^{2}$ \\ Manuela Albertelli ${ }^{1}$ \\ Federico Gatto ${ }^{1}$ \\ Francesco Cocchiara ${ }^{1}$ \\ Laura Roffredo 1 \\ Francesco Minuto ${ }^{1}$ \\ Paolo Magni2 \\ Diego Ferone ${ }^{1}$
}

${ }^{1}$ Department of Internal Medicine and Center of Excellence for Biomedical Research, University of Genoa, Italy

2 Department of Pharmacological Sciences and Biomolecular, University of Study of Milan, Italy

\section{Diego Ferone \\ University of Genoa \\ Viale Benedetto XV, 6 \\ 16132 Genoa, Italy \\ E-mail: ferone@unige.it}

Address for correspondence:

Department of Internal Medicine and Center of Excellence for Biomedical Research

\section{Summary}

The evidence that prostate cancer $(\mathrm{PCa})$ expresses specific receptors for hormones and neuropeptides, including somatostatin (SRIF) receptors (SSRs) has driven the research towards the identification of new potential diagnostic/therapeutic paths besides the conventional treatment options. Although the first attempts has led to inconclusive results due to the heterogeneity of this tumor and to the complex mechanisms involved in the progression of $\mathrm{PCa}$ tumor growth, the potential role of SRIF and its synthetic analogues (SSAs) in the treatment of $\mathrm{PCa}$ represents an "open challenge" in the light of the new knowledge about SSR pathophysiology. Indeed, SRIF and SSAs can control tumor cell proliferation by two separate mechanisms: a direct mechanism through the activation of the five specific SSRs or an indirect mechanism through the inhibition of secretion of several growth factors and hormones responsible for tumor cell proliferation. Since new SSAs specific for each receptor subtype, as well as bi-specific compounds and panligands have been synthetized, the identification of alternative SSR tar- gets on PCa cells and the consequent employment of these new specific molecules in the treatment of advanced PCa (alone or in combination with traditional treatment options), could improve the prognosis particularly of those patients not responding to (anti-) hormonal therapy (hormone-refractory $\mathrm{PCa}$ patients).

KEY WORDS: somatostatin receptors, prostate, cancer, tumor progression, octreotide, lanreotide.

\section{Introduction}

PCa represents the second most common malignancy after lung cancer in males (1). Since about $70 \%$ of prostate neoplasms show an androgen-dependent phenotype, androgen-deprivation is currently the preferred primary treatment for hormone responsive $\mathrm{PCa}$. Conversely, therapy is very limited for hormone refractory prostate cancer (HRPCa) in which neuroendocrine differentiation (NED) seems to play a critical role in disease progression toward castration resistance. Because chemotherapy minimally improves survival of patients with HRPCa, there is increasing interest in exploring innovative therapeutic approaches through better tolerated and effective drugs. Improved understanding of PCa biology has led to new promising treatment strategies, in particular peptide-based agonists and antagonists, including somatostatin (SRIF) analogs (SSAs), alone or in combination with other treatments (2-4).

SRIF is a cyclic polypeptidic hormone largely expressed in hypothalamus which displays inhibitory functions on hormone secretion (5-18) and cell proliferation $(14,19,20)$. SRIF acts through the binding with five specific membrane receptors (SSRs) codenamed SS1R-5 (21). All SSRs functionally couple to G proteins and belong to the seven-transmembrane segment receptor superfamily (22). Since SSRs mainly exert inhibitory functions, selective agonists targeting these receptors have been developed for the treatment of a number of neuroendocrine disorders. Besides pituitary, SSRs are heterogeneously expressed in numerous normal and neoplastic tissues. Interestingly, SSRs are highly expressed in PCa (23-29) and, in particular, in HRPCa (30). Clinical studies testing the currently available SSAs on patients with HRPCa showed conflicting and non-conclusive results, probably due to the prevalent SS2R specificity of these drugs. At this purpose, new targeted agents based on different receptor affinity or more complex SSAs are 
Table 1 - SRIF, SRIF analogs and SRIF/DA chimeric compounds: human SRIF receptor subtype (SSRs) specificity (IC50-nM).

\begin{tabular}{|c|c|c|c|c|c|c|}
\hline \multirow{2}{*}{ LIGANDS } & \multicolumn{6}{|c|}{ Binding affinity } \\
\hline & SS1R & SS2R & SS3R & SS4R & SS5R & D2R \\
\hline \multicolumn{7}{|c|}{ Natural ligands } \\
\hline SRIF-14 & $0.1-2.26$ & $0,2-1.3$ & $0.3-1.6$ & $0.3-1.8$ & $0.2-0.9$ & l \\
\hline SRIF-28 & $0.1-2.2$ & $0.2-4.1$ & $0.3-6.1$ & $0.3-7.2$ & $0.05-0.4$ & 1 \\
\hline SSAS & & & & & 8 & $\theta$ \\
\hline Octreotide & $>1000$ & $0.4-2.1$ & 4.4-34.5 & $>1000$ & $5.6-32$ & I \\
\hline Lanreotide & $>1000$ & $0.5-1.8$ & $43-107$ & $>1000$ & $0.6-14$ & I \\
\hline Pasireotide & 9.3 & 1 & 1.5 & $>100$ & 0.16 & I \\
\hline Vapreotide & $>1000$ & $0.2-5.4$ & 31 & 45 & 0.7 & 1 \\
\hline BIM-23014 & $>1000$ & 0.75 & 98 & $>1000$ & 12.7 & 1 \\
\hline BIM-23926 & 4 & $>1000$ & $>1000$ & $>1000$ & $>1000$ & I \\
\hline BIM-23120 & $>1000$ & 0.34 & 412 & $>1000$ & 213,5 & I \\
\hline BIM-23704 & 6.3 & 1.4 & 43.2 & $>1000$ & 115 & 1 \\
\hline BIM-23206 & $>1000$ & 166 & $>1000$ & $>1000$ & 2.4 & I \\
\hline BIM-23244 & $>1000$ & 0.29 & 133 & $>1000$ & 0.67 & 1 \\
\hline BIM-23268 & 18.4 & 15.1 & 61.6 & 16.3 & 0.37 & I \\
\hline BIM-23745 & 42 & $>1000$ & $>1000$ & $>1000$ & $>1000$ & l \\
\hline BIM-23190 & $>1000$ & 0.35 & 215 & $>1000$ & 11.2 & I \\
\hline BIM-23A799 & 2.5 & 0.3 & 0.6 & $>1000$ & 0.6 & 1 \\
\hline Dopamine (D & 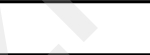 & & & & & \\
\hline BIM-52097 & I & / & l & / & / & 22.1 \\
\hline \multicolumn{7}{|c|}{ Chimeric SRIF/DA compounds } \\
\hline BIM-23A757 & ND & 0.58 & ND & ND & 104.4 & 7.9 \\
\hline BIM-23760 & 622 & 0.03 & 160 & $>1000$ & 42 & 15 \\
\hline BIM-23A761 & ND & 0.01 & ND & ND & 3.7 & 27 \\
\hline
\end{tabular}

under development to overcome the limitations of the current molecules. Recently, mono- and bi-specific SSAs (BIMs), as well as the pan-ligand pasireotide (SOM 230) have been developed and their role in the control of tumor growth has been explored in the last years (Tab. 1).

Aim of this review is to focus on the new knowledge about the role of the SSRs and SSAs in the control of $\mathrm{PCa}$ tumor growth.

\section{Prostate cancer}

$\mathrm{PCa}$ is the most common tumor among men and, in general, represents the second cause of death after lung cancer (31). Age, race, familiarity, hormonal levels, and environmental factors represent the most frequent risk factors involved in $\mathrm{PCa}$ onset. In $70 \%$ of cases, $\mathrm{PCa}$ is localized in the peripheral back area of prostate gland and shows an androgen-dependent phenotype. Histologically, majority of PCa are well-differentiated adenocarcinomas $(32,33)$. Gleason score is the most common method to classify PCa (34). According to this system, neoplasia are classified in five groups on the basis of the glandular localization and differentiation degree, being "grade 1" the well-differentiated neoplasia and "grade 5" the non-differentiated tumours (showing no glandular differentiation). This classification is extremely important in $\mathrm{PCa}$ since 
it affects the right therapeutic choice.

Besides surgical orchiectomy, the first-line standard treatment for patients with hormone-sensitive disease is an androgen deprivation obtained by using luteinizing hormone releasing-hormone (LHRH) agonists and anti-androgens, alone or in combination. In general, patients undergoing hormonal therapy respond to the treatment lowering the plasmatic levels of prostatespecific antigen (PSA) and reducing tumor mass.

\section{Neuroendocrine differentiation of prostate cancer} In a high percentage of $\mathrm{PCa}$ patients, responding to hormonal treatment, after a period of quiescence cells tend to lose their glandular differentiation and to acquire a neuroendocrine phenotype releasing from androgen dependence (HRPCa). This progression is related to a disease worsening and a bad prognosis (32). The median survival for patients with HRPCa is less than one year, and the available treatment options, including chemotherapy, are only palliative (35). Neuroendocrine cells (NE) are scattered throughout normal prostate and represent the third type of epithelial cells (36). Similarly to NE cells in general, prostate NE cells show an epithelial phenotype, the presence of secretory granules, neuron specific enolase (NSE) and cromogranin $\mathrm{A}(\mathrm{CgA})$ immunoreactivity etc. Moreover, they do not show a high proliferation rate and do not express androgen receptors, indicating that they can function independently from androgen regulation (37). The function of NE cells in prostate gland is still unclear but they are supposed to be involved in the growth and differentiation of the normal gland, as well as in the regulation of hormone secretion of the mature gland.

Being independent from the androgenic regulation, prostate NE cell growth is regulated by other growth factors, the most representative being the epidermal growth factor (EGF) (38). The main secretory product of prostate NE cells is $\mathrm{CgA}$, member of the acidic secretion proteins. It has been demonstrated that high plasmatic levels of $\mathrm{CgA}$ represent an important marker of neuroendocrine differentiation of PCa (39).

Moreover, during $\mathrm{PCa}$ progression process, there is either a selection of clones which escape the anti-androgen therapy (androgen-independent) or an increase of NE cells leading to a more aggressive tumour with a worse prognosis (40).

It has been also hypothesized that PCa NE cells do not derive from normal NE cells but from a transformation of benign esocrine epithelial cells that occurs during tumor progression (41). Androgen-independent $\mathrm{PCa}$ tumor growth seems to be regulated by several mechanisms, but it is principally modulated by the autocrine-paracrine action of neuropeptides secreted by NE cells (42). NE cells can also indirectly contribute to "protect" neoplastic cell proliferation through an increase of the anti-apoptotic activity mediated by the iperexpression of bcl-2 (43). According to this concept, NE cells produce a protective antiapoptotic effect for neoplastic cells which can proliferate independently from androgenic stimulation. The evidence that in vi$v o$, the response of neoplastic cells to antineoplastic therapies is directly influenced by microenvironment in which they proliferate, has led to the concept of $\mathrm{PCa}$ "antisurvival factor therapy".

In this context, the characterization of SSR profile of $\mathrm{PCa}$ cells could represent the basis for the development of new therapeutic strategies using specific SSAs.

\section{Somatostatin system}

SRIF is a cyclic polypeptidic hormone largely expressed in hypothalamus which displays inhibitory functions on hormone secretion (5-18) and cell proliferation $(14,19,20)$. SRIF acts on target cells through its binding with five specific receptor subtypes codenamed SS1R-SS5R $(21,22,44,45)$. They belong to the super family of G-protein coupled receptors (GPCRs) and present seven transmembrane domains. The binding of SRIF with SSRs inhibits the secretion of a wide range of hormones, including the pituitary GH, PRL and TSH and mediates cytostatic effects and cell cycle arrest in G0/G1, or apoptosis of tumoral cells both in vitro and in vivo (46) (Fig. 1). Depending on the different cell type, the binding of SRIF with SSRs leads to an interaction of the activated receptors with specific G-proteins (22) activating different intracellular pathways such as adenylyl and guanylyl cyclases, phospholypase $\mathrm{A} 2$ and $\mathrm{C}, \mathrm{K}+$ and $\mathrm{Ca} 2+$ channels, $\mathrm{Na}+\mathrm{H}+$ pumps MAP kinase, thyrosin-phosphatase and $\operatorname{Src}(21,44,46-50)$. The enrolment of different G-proteins and, consequently, the activation of different intracellular pathways, represents the basis of the functional diversity of these receptors (51). In particular, hormone secretion is mainly regulated by the inhibition of cAMP production and $\mathrm{Ca} 2+$ flows. Conversely, the cytostatic effect on cell cycle is mediated by the activation of membrane phosphotyrosine phosphatases (PTPases) $(46,49)$, which, in turn, control the activity of a number of downstream signaling molecules, particularly mitogen activated protein kinase (MAPK, such as ERK1/2), cyclin-dependent kinase inhibitors (CDKI, such as p27kip1 and p21cip1/waf1), and phosphatidylinositol 3-kinase (PI3K)/AKT signalling pathway (52). PTPs are also able to alter growth factor (GF) signalling through the selective dephosphorylation and inactivation of GF receptors such as PDGF-R, VEGF-R2, insulin- $R$ and EGFR, indirectly inhibiting cell proliferation (49).

Recent studies demonstrated that the binding of SRIF and SSAs to SS3R, and possibly to SS2R as well, can induce apoptosis (53).

Although a $40-60 \%$ homology exists among SSRs, each receptor subtype triggers different biologic functions. Particularly, SS2R and SS5R are involved in the control of GH secretion and SS5R is also able to modulate insulin and glucagone release. SS3R and, at a less extent SS2R, can induce apoptosis, while SS1R, SS4R, and SS5R are mainly involved in the inhibition of cell proliferation, as well as in neurotransmission. 


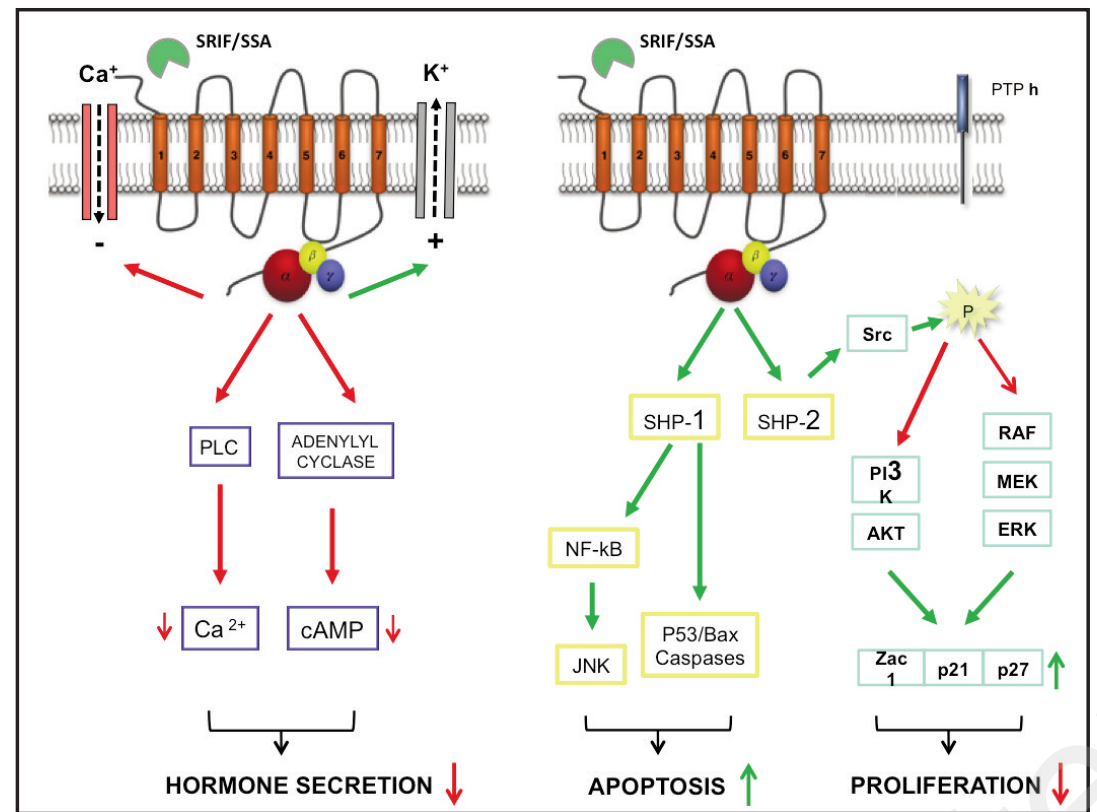

Figure 1. Principal intracellular signalling cascades associated to the binding of SRIF14 / analogs with SRIF receptors. Red arrows represent an inhibitory effect; green arrows represent a stimulatory effect.

Legend: SSR: somatostatin receptor; PTP: phosphothyrosine phosphatases; IP3K: phosphatidylinositol 3-kinase; RAF, MEK,ERK: protein kinases belonging to MAPK/ERK signal transduction pathway; SHP-1 and SHP-2: Src homology region 2 domain-containing phosphatase -1/-2; NF-kB: nuclear factor kappa-light-chainenhancer of activated B cells; JNK: c-Jun N-terminal kinases.

\section{Somatostatin receptors in prostate cancer}

Besides pituitary, SSRs are heterogeneously expressed in numerous normal and neoplastic tissues $(20,54)$, including prostate and PCa $(23,24,26-29)$, showing a tissue-specific distribution (54-57). Moreover, it has been demonstrated that almost all SRIF target tissues express different receptor subtypes simultaneously (55).

Several studies aimed to define the expression of SSRs among epithelial and stromal cells in PCa tissues both at mRNA and protein levels $(23,25)$, their expression in the different stage of disease $(26,58)$ and their modulation by hormonal treatment (30). In any case, all results demonstrated a heterogeneous SSR expression in $\mathrm{PCa}$, either in terms of amount of each specific receptor subtype in different stage of disease or in terms of distribution among epithelial and stromal cells. In detail, Mazzucchelli et al. described that all five SSRs were expressed in cytoplasm of epithelial cell but only SS3R and SS4R were expressed on cell membrane lowering their expression from normal-looking epithelium to high-grade prostate intraepithelial neoplasia (HGPIN) and $\mathrm{PCa}$ $(30-90 \%)$. Moreover another study of the same group demonstrated a further decrease of SS3R and SS4R membrane expression (20-70\%) from HGPIN/PCa and HRPCa. Conversely, Sinisi et al. demonstrated that SS3R mRNA (and, consequently, the protein) was not expressed either in $\mathrm{PCa}$ or normal epithelial cells cultured from PCa biopsies while SS2R was only expressed in epithelial cells of normal prostate tissue and was absent in PCa (23). SS1R was only expressed in PCa epithelial cells while SS4R and SS5R were expressed both in normal and $\mathrm{PCa}$ epithelial cells. No SS1R, $-2,-3,-4$, and -5 were found in stromal cells either in normal or in PCa (23).
A further different description of SSR expression and distribution in PCa tissue comes from Dizey et al. This group evaluated SSR expression in PCa tissues from radical prostatectomy by immunohistochemistry demonstrating SS1R staining in tumor and neuroendocrine cells, SS2R staining in stromal cells, peritumoral blood vessels and tumor cells, SS3R staining in benigne prostatic hyperplasia $(\mathrm{BPH})$ and $\mathrm{PCa}$ epithelial cells, SS4R strong immunostaining in $\mathrm{PCa}$ epithelial cells and low expression in BPH. No SS5R expression was detected in PCa tissues (26).

Moreover, recent studies on androgen-dependent and -independent PCa cell lines demonstrated the constitutive expression of specific SSRs (26) or all SSRs (27), as well as the constitutive expression of SSR hetero-dimers and SSR/dopamine receptor-2 (D2R) dimers on PCa cell membrane (28) (Fig. 2), these latter once activated by specific ligands, displaying an enhanced antiproliferative activity. Moreover, Ruscica et al. demonstrated a modulation of SSR expression depending on the presence of growth factors and/or steroid hormones in the culture microenvironment (27). In particular, these authors clearly demonstrated that, mimicking a steroid deprivation by a switch of FBS supplement from 10\% (regular culture conditions) to $2 \%$, SS1R and SS3R were up-regulated (both at mRNA and protein level), while no changes were observed for SS2R and SS5R (27).

In these studies the only receptor subtype which was demonstrated to be constantly expressed was SS1R. Furthermore, Reubi et al. confirmed that SS1R is the receptor subtype mainly expressed in $\mathrm{PCa}$ tissue (59), whereas Kosari et al. demonstrated a significant correlation between the amount of SS1R gene expression and PCa progression. In detail, this group showed that, among a number of candidate variably 


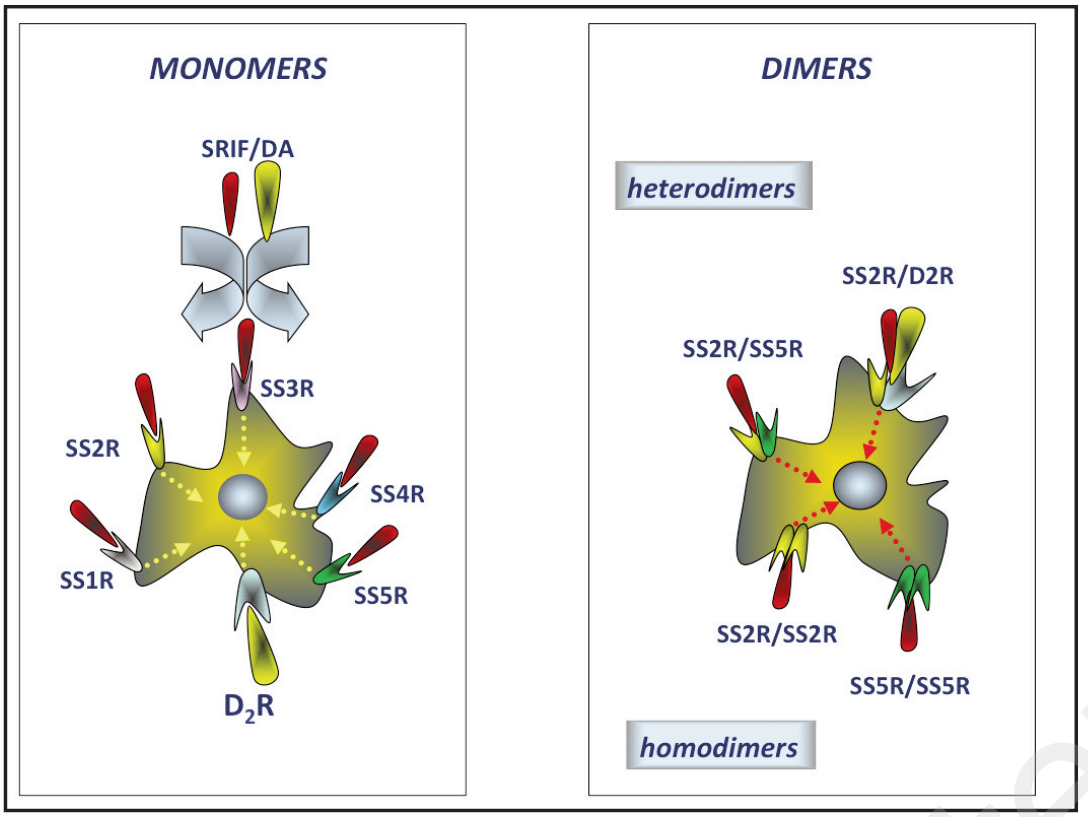

Figure 2. Schematic representation of SSR/D2R homo- and hetero-dimerization. In order to simplify the figure, only SS2R, SS5R and D2R were considered.

overexpressed genes selected for their association with aggressive PCa phenotype, the most prominent candidate, besides genes already known to be related to proliferation or cell cycle control, was SS1R (60).

In this context, these findings could lead to consider SS1R a good prognostic marker for PCa classification, as well as a good target for the development of new drugs acting through this receptor subtype.

\section{Somatostatin analogues and prostate cancer}

After an excellent initial response to combined androgen blockade therapy, in approximately 2-3 years, most PCas progress to a hormone-refractory (HR) stage with increased growth, invasion and malignancy (61). Since the available treatment options for these patients are palliative, new cancer therapies based on peptide analogues could provide a promising strategy for the management of advanced PCa (62). Among the analogues of peptide hormones, SSAs have gained the most attention because of their antineoplastic effects, such as decreased tumor cell growth and angiogenesis, as well as an increased cancer cell apoptosis (26) (Tab. 1).

First data on the parenteral use of octreotide, as an adjuvant therapy, demonstrated that treatment with this SRIF analogue causes a moderate suppression of the growth of transplanted Dunning R3327-H prostate tumors in the rat (63). Regarding clinical studies, the results obtained in trials conducted on advanced HRPCa patients using lanreotide are conflicting and not conclusive. In 1995, a 12 weeks Phasel-II study on 30 patients with HRPCa, treated with a slow-release formulation of lanreotide (30 mg i.m. weekly), showed that the performance status and bone pain were improved in $40 \%$ and $35 \%$ of patients, respectively, and $20 \%$ of them had a decrease of at least $50 \%$ in PSA levels (64). Conversely, a phase-I study conducted on 25 patients with metastatic HRPCa treated with a continuous intravenous infusion of lanreotide, totalling $24 \mathrm{mg} / \mathrm{day}$, did not show any clinical response by either radiographic or tumor marker criteria (65). In 2006 a randomized controlled clinical trial on HRPCa patients demonstrated that the combination of octreotide $(20 \mathrm{mg}$ i.m. every 28 days), oral dexamethasone (4 mg daily for 1 month) plus zoledronate (a bisphosphonate interfering with bone remodeling) vs zoledronate alone, resulted in a better outcome with respect to median progression-free survival, median PCa-specific overall survival and median duration of bone pain improvement (66).

Since peptide receptors are often expressed in many primary tumors, they can be targeted by a specific peptide as well as by different labelled analogs (67). Hence, peptides as potential therapeutics or drug-delivering vehicles, possess a number of attractive characteristics such as rapid circulatory clearance and good tumor tissue-penetrating ability. In this context, the use of the hybrid analogue $\mathrm{AN}-238$, consisting of 2-pyrrolinodoxorubicin (AN-201) and carrier RC-121, has been shown to be highly effective in SS2R-positive anaplastic Dunning R-3327 AT-1 rat PCa at a nontoxic dose. In contrast, the cytotoxic radical and the carrier protein, administered separately, were ineffective and toxic (68). In line with these data, a recent in vitro study reported that lanreotide could interact with docetaxel in HRPCa cells, with possible explanatory mechanisms involving the regulation of the interaction of P-glycoprotein-mediated docetaxel through lanreotide (69). This latter evidence was corroborate by the same authors which also demonstrated that octreotide and docetaxel combination increase HRPCa cell death through cell cycle regulation and induction of apoptosis (70). 


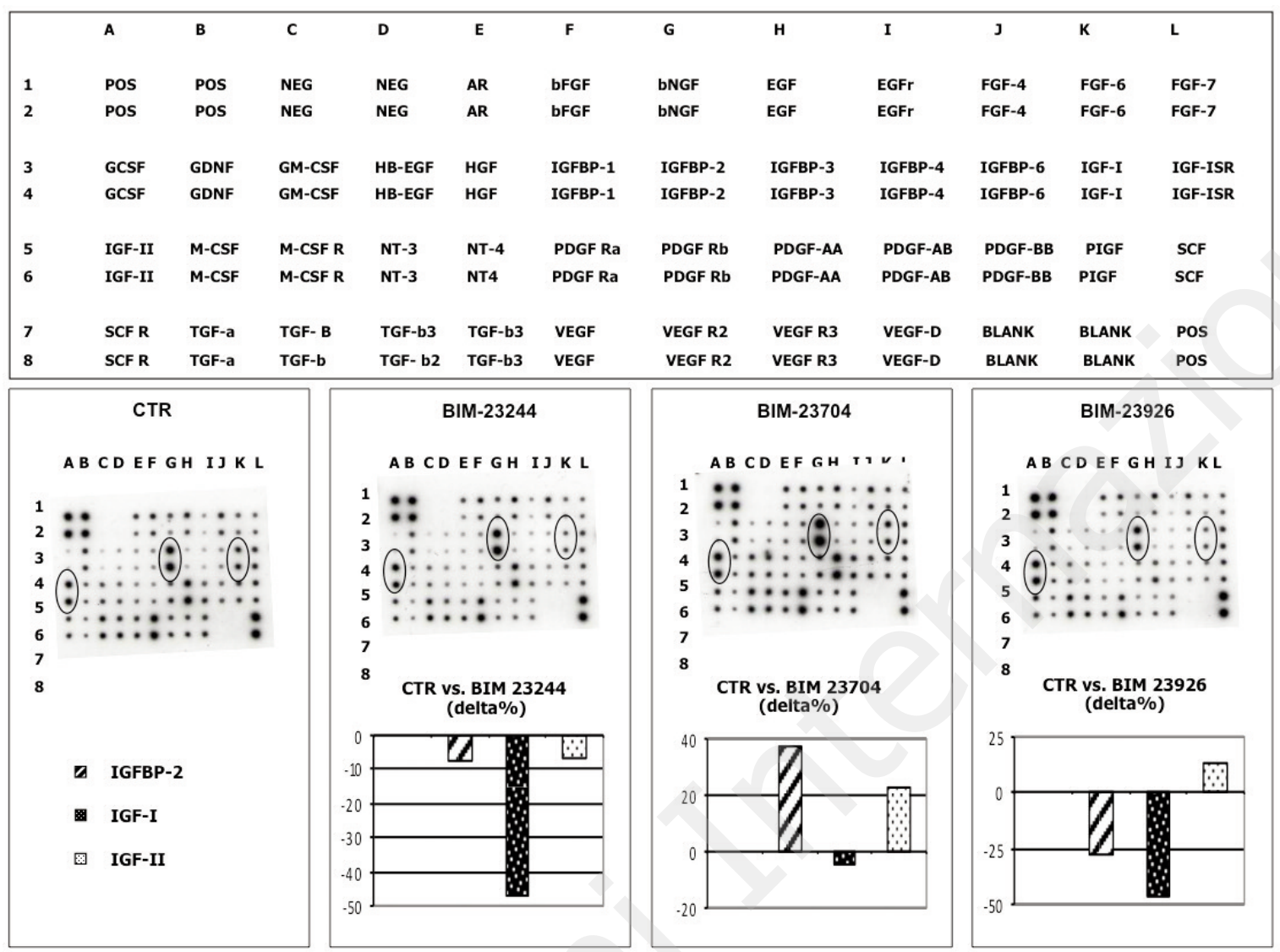

Figure 3. Effect of SSA treatment on growth factor secretion in LNCaP cells. Cells were treated for 48h with the SS2R/SS5R bi-specific compound BIM-23244, SS1R/SS2R bi-specific compound BIM-23704 and SS1R mono-specific compound BIM23926 (all compounds 10-8 M). After the incubation time, conditioned media were collected and analyzed by protein array method. In the upper part of the figure all growth factors are listed in the same sequence as they appear, as spot, in the blots below. At the bottom of the figure, histograms represent the densitometric analysis of IGF-I, IGF-II and IGFBP-2 after BIM treatment, expressed as delta\% vs untreated cells (CTR).

The most frequent problem arising from $\mathrm{PCa}$ is its propensity to metastasize following local invasion, one of the early steps in tumor spreading. In this context, octreotide has been shown to inhibit the migration and invasion aptitudes of DU-145 and PC-3 human androgen-independent cells (71). Nevertheless, the multistep process of invasion is supported by the synthesis of new proteins, lipids, and nucleic acids which is critical for cell growth and division. Interestingly, Yan demonstrated that smsDX SRIF derivate inhibited the invasiveness of PCa cells by deregulating metabolic enzymes (glycolysis, tricarboxylic acid cycle, pentose phosphate, glutaminolysis and oxidative phosphorylation) and proteins which are involved in the process of HRPCa cell invasiveness and survival (72).

As already mentioned above, SSRs can be expressed on cell membrane of target tissues not only as monomers but also as omo- or hetero-dimers. Based on this novelty in the field of SSR, recent studies aimed to evaluate the activity of SSR dimers in regulating tumor cell proliferation. At this purpose, an in vitro study by Ruscica et al. on the human-androgen dependent LNCaP cell line demonstrated that the
SS2R/SS5R bi-specific compound, BIM-23244, was able to significantly induce/stabilize SS2R/SS5R dimer and modulate IGF-I secretion (Fig. 3), thus inducing a set of complementary favorable events in terms of antiproliferative activity (27). Moreover, the same group demonstrated that, besides the SS2R/SS5R-driven antiproliferative/antisecretive actions, only the SS1R mono-specific compound, BIM23926, was able to significantly inhibit PCa cell proliferation (-28/-36\% vs. untreated cells) even at low doses. This effect was demonstrated not only in the androgen-dependent PCa cell line LNCaP but also in the androgen-independent PCa cell lines, DU-145 and PC-3 (Ruscica et al., unpublished data) ascribing to SS1R a crucial role in the control of cell proliferation in these tumor cells.

Similarly, another study investigated the effect of a new generation of chimeric "dopastatins" in LNCaP cells endogenously expressing SSRs and D2R, observing, for the first time, a direct and significant positive correlation between the amount of ligand induced SS5R/D2R dimers and the magnitude of the antiproliferative effect. 


\section{Conclusion and new prospectives}

In this review, we pointed out that SSRs expression in PCa can vary depending on the different stage of disease, hormonal treatment and presence of factors in the microenvironment able to modify quantitatively and, perhaps also qualitatively, SSR profile. Moreover, all studies evaluating the effect of the commercially available SSAs (commonly used in clinical practice) in the control of PCa growth, showed inconclusive results so far, probably due to the prevalent SS2R specificity of these drugs. In this context, according to the recent data demonstrating either the inefficacy of SS2R monospecific compounds in the inhibition of cell proliferation or the significant effect of a SS1R and SS2R/SS5R specific compounds in androgen-dependent and -independent PCa cell lines, SS1R and SS2R/SS5R dimer have been emerging as the most functional and representative SSRs in PCa. Moreover, regarding SS1R, which gene has been demonstrated to be up-regulated in the progression of PCa towards a more aggressive phenotype, could represent a new target for the development of innovative treatment strategies.

\section{References}

1. Dayyani F, Gallick GE, Logothetis CJ, Corn PG. Novel therapies for metastatic castrate-resistant prostate cancer. J Natl Cancer Inst 2011; 103(22): 1665-75.

2. Xu Y, Jiang YF, Wu B. New agonist- and antagonistbased treatment approaches for advanced prostate cancer. J Int Med Res 2012; 40(4): 1217-26.

3. Toulis KA, Goulis DG, Msaouel P, Koutsilieris M. Dexamethasone plus somatostatin-analog manipulation as bone metastasis microenvironment-targeting therapy for the treatment of castration-resistant prostate cancer: a meta-analysis of uncontrolled studies. Anticancer Res 2012; 32(8): 3283-9.

4. Lattanzio L, Tonissi F, Monteverde M, Milano G, Merlano MC, Lo Nigro C. Differential molecular mechanism of docetaxel-octreotide combined treatment according to the docetaxel-resistance status in PC3 prostate cancer cells. Anticancer Drugs 2013; 24(2): 120-30.

5. Konturek SJ, Tasler J, Obtulowicz W, Coy DH, Schally AV. Effect of growth hormone-release inhibiting hormone on hormones stimulating exocrine pancreatic secretion. J Clin Invest 1976; 58(1): 1-6.

6. Raptis S, Schlegel W, Lehmann E, Dollinger HC, Zoupas C. Effects of somatostatin on the exocrine pancreas and the release of duodenal hormones. Metabolism 1978; 27(9 Suppl 1): 1321-8.

7. Zabel BU, Naylor SL, Sakaguchi AY, Bell GI, Shows TB. High-resolution chromosomal localization of human genes for amylase, proopiomelanocortin, somatostatin, and a DNA fragment (D3S1) by in situ hybridization. Proc Natl Acad Sci U S A 1983; 80(22): 6932-6.

8. Kraenzlin ME, Wood SM, Neufeld M, Adrian TE,
Bloom SR. Effect of long acting somatostatin-analogue, SMS 201 995, on gut hormone secretion in normal subjects. Experientia 1985; 41(6): 738-40.

9. Hugues JN, Epelbaum J, Voirol MJ, Sebaoun J, Kordon C, Enjalbert A. Involvement of endogenous somatostatin in the regulation of thyrotroph secretion during acute and chronic changes in diet. Neuroendocrinology 1986; 43(3): 435-9.

10. Williams G, Fuessl H, Kraenzlin M, Bloom SR. Postprandial effects of SMS 201-995 on gut hormones and glucose tolerance. Scand J Gastroenterol Suppl 1986; 119: 73-83.

11. Chen C, Israel JM, Vincent JD. Electrophysiological responses to somatostatin of rat hypophysial cells in somatotroph-enriched primary cultures. J Physiol 1989; 408: 493-510.

12. Bertherat J, Bluet-Pajot MT, Epelbaum J. Neuroendocrine regulation of growth hormone. Eur $\mathrm{J}$ Endocrinol 1995; 132(1): 12-24.

13. Le Romancer M, Cherifi $Y$, Levasseur S, Laigneau JP, Peranzi G, Jais P, et al. Messenger RNA expression of somatostatin receptor subtypes in human and rat gastric mucosae. Life Sci 1996; 58(13): 1091-8.

14. Shimon I, Taylor JE, Dong JZ, Bitonte RA, Kim S, Morgan B, et al. Somatostatin receptor subtype specificity in human fetal pituitary cultures. Differential role of SS2R and SS5R for growth hormone, thyroid-stimulating hormone, and prolactin regulation. J Clin Invest 1997; 99(4): 789-98.

15. Chen $\mathrm{C} . \mathrm{G}(\mathrm{o}) 2$ and $\mathrm{Gi} 3$ proteins mediate the action of somatostatin on membrane $\mathrm{Ca} 2+$ and $\mathrm{K}+$ currents in ovine pituitary somatotrophs. Clin Exp Pharmacol Physiol 1997; 24(8): 639-45.

16. Bluet-Pajot MT, Epelbaum J, Gourdji D, Hammond C, Kordon C. Hypothalamic and hypophyseal regulation of growth hormone secretion. Cell Mol Neurobiol 1998; 18(1): 101-23.

17. Kreienkamp HJ, Akgun E, Baumeister H, Meyerhof W, Richter D. Somatostatin receptor subtype 1 modulates basal inhibition of growth hormone release in somatotrophs. FEBS Lett 1999; 462(3): 464-6.

18. Rohrer SP Schaeffer JM. Identification and characterization of subtype selective somatostatin receptor agonists. J Physiol Paris 2000; 94(3-4): 211-5.

19. Florio T. Molecular mechanisms of the antiproliferative activity of somatostatin receptors (SSRs) in neuroendocrine tumors. Front Biosci 2008; 13: 822-40.

20. Ruscica M, Arvigo M, Steffani L, Ferone D, Magni P. Somatostatin, somatostatin analogs and somatostatin receptor dynamics in the biology of cancer progression. Curr Mol Med 2013; 13(4): 555-71.

21. Patel YC. Somatostatin and its receptor family. Front Neuroendocrinol 1999; 20(3): 157-98.

22. Moller LN, Stidsen CE, Hartmann B, Holst JJ. Somatostatin receptors. Biochim Biophys Acta 2003; 1616(1): 1-84.

23. Sinisi AA, Bellastella A, Prezioso D, Nicchio MR, Lotti T, Salvatore M, et al. Different expression patterns of somatostatin receptor subtypes in cultured epithelial cells from human normal prostate and prostate cancer. J Clin Endocrinol Metab 1997; 82(8): 2566-9. 
24. Benali N, Ferjoux G, Puente E, Buscail L, Susini C. Somatostatin receptors. Digestion 2000; 62 Suppl 1: 27-32.

25. Halmos G, Schally AV, Sun B, Davis R, Bostwick DG, Plonowski A. High expression of somatostatin receptors and messenger ribonucleic acid for its receptor subtypes in organ-confined and locally advanced human prostate cancers. J Clin Endocrinol Metab 2000; 85(7): 2564-71.

26. Dizeyi N, Konrad L, Bjartell A, Wu H, Gadaleanu V, Hansson J, et al. Localization and mRNA expression of somatostatin receptor subtypes in human prostatic tissue and prostate cancer cell lines. Urol Oncol 2002; 7(3): 91-8.

27. Ruscica M, Arvigo M, Gatto F, Dozio E, Feltrin D, Culler MD, et al. Regulation of prostate cancer cell proliferation by somatostatin receptor activation. Mol Cell Endocrinol 2010; 315(1-2): 254-62.

28. Arvigo M, Gatto F, Ruscica M, Ameri P, Dozio E, Albertelli $\mathrm{M}$, et al. Somatostatin and dopamine receptor interaction in prostate and lung cancer cell lines. J Endocrinol 2010; 207(3): 309-17.

29. Mazzucchelli R, Scarpelli M, Lopez-Beltran A, Cheng L, Di Primio R, Bono A, et al. Immunohistochemical expression and localization of somatostatin receptors in normal prostate, high grade prostatic intraepithelial neoplasia and prostate cancer and its many faces. J Biol Regul Homeost Agents 2012; 26(2): 181-92.

30. Mazzucchelli R, Morichetti $D$, Santinelli A, Scarpelli M, Bono AV, Lopez-Beltran A, et al. Immunohistochemical expression and localization of somatostatin receptor subtypes in androgen ablated prostate cancer. Cell Oncol (Dordr) 2011; 34(3): 235-43.

31. Boring CC, Squires TS, Tong T, Montgomery S. Cancer statistics, 1994. CA Cancer J Clin 1994; 44(1): 726.

32. Bostwick DG, Pacelli A, Lopez-Beltran A. Molecular biology of prostatic intraepithelial neoplasia. Prostate 1996; 29(2): 117-34.

33. Mostofi FK, Davis CJ Jr., Sesterhenn IA. Pathology of carcinoma of the prostate. Cancer 1992; 70(1 Suppl): 235-53.

34. Deshmukh N, Foster CS. Grading prostate cancer. Pathology of the Prostate1997: Philadelphia: WB Saunders.

35. Plonowski A, Schally AV, Nagy A, Sun B, Szepeshazi $K$. Inhibition of PC-3 human androgen-independent prostate cancer and its metastases by cytotoxic somatostatin analogue AN-238. Cancer Res 1999; 59(8): 1947-53.

36. Abrahamsson PA, Wadstrom LB, Alumets J, Falkmer S, Grimelius L. Peptide-hormone- and serotonin-immunoreactive cells in normal and hyperplastic prostate glands. Pathol Res Pract 1986; 181(6): 675-83.

37. Nakada SY, di Sant'Agnese PA, Moynes RA, Hiipakka RA, Liao S, Cockett AT, et al. The androgen receptor status of neuroendocrine cells in human benign and malignant prostatic tissue. Cancer Res 1993; 53(9): 1967-70.

38. Iwamura M, Koshiba K, Cockett AT. Receptors for $\mathrm{BPH}$ growth factors are located in some neuroendocrine cells. Prostate Suppl 1998; 8: 14-7.
39. Berruti A, Mosca A, Tucci M, Terrone C, Torta M, Tarabuzzi R, et al. Independent prognostic role of circulating chromogranin A in prostate cancer patients with hormone-refractory disease. Endocr Relat Cancer 2005; 12(1): 109-17.

40. Mosca A, Berruti A, Russo L, Torta M, Dogliotti L. The neuroendocrine phenotype in prostate cancer: basic and clinical aspects. J Endocrinol Invest 2005; 28(11 Suppl International): 141-5.

41. Bonkhoff H, Stein U, Remberger K. Multidirectiona differentiation in the normal, hyperplastic, and neoplastic human prostate: simultaneous demonstration of cell-specific epithelial markers. Hum Pathol 1994; 25(1): 42-6.

42. Sciarra A, Cardi A, Dattilo C, Mariotti G, Di Monaco $F$, Di Silverio F. New perspective in the management of neuroendocrine differentiation in prostate adenocarcinoma. Int J Clin Pract 2006; 60(4): 462-70.

43. Anvari K, Seilanian Toussi M, Kalantari M, Naseri S, Karimi Shahri M, Ahmadnia $\mathrm{H}$, et al. Expression of $\mathrm{Bcl}-2$ and $\mathrm{Bax}$ in advanced or metastatic prostate carcinoma. Urol J 2012; 9(1): 381-8.

44. Lamberts SW, van der Lely AJ, Hofland LJ. New somatostatin analogs: will they fulfil old promises? Eur $J$ Endocrinol 2002; 146(5): 701-5.

45. Ferjoux G, Bousquet C, Cordelier P, Benali N, Lopez $F$, Rochaix $P$, et al. Signal transduction of somatostatin receptors negatively controlling cell proliferation. J Physiol Paris 2000; 94(3-4): 205-10.

46. Weckbecker G, Lewis I, Albert R, Schmid HA, Hoyer $\mathrm{D}$, Bruns $\mathrm{C}$. Opportunities in somatostatin research: biological, chemical and therapeutic aspects. Nat Rev Drug Discov 2003; 2(12): 999-1017.

47. Lamberts SW, Krenning EP, Klijn JG, Reubi JC. Clinical applications of somatostatin analogs. Trends Endocrinol Metab 1990; 1(3): 139-44.

48. Lamberts SW, van der Lely AJ, de Herder WW, Hofland LJ. Octreotide. N Engl J Med 1996; 334(4): 246-54.

49. Florio T. Somatostatin/somatostatin receptor signalling: phosphotyrosine phosphatases. Mol Cell Endocrinol 2008; 286(1-2): 40-8.

50. Brazeau P, Vale W, Burgus R, Ling N, Butcher M, Rivier J, et al. Hypothalamic polypeptide that inhibits the secretion of immunoreactive pituitary growth hormone. Science 1973; 179(4068): 77-9.

51. Law SF, Woulfe D, Reisine T. Somatostatin receptor activation of cellular effector systems. Cell Signal 1995; 7(1): 1-8.

52. Theodoropoulou M, Zhang J, Laupheimer S, PaezPereda M, Erneux C, Florio T, et al. Octreotide, a somatostatin analogue, mediates its antiproliferative action in pituitary tumor cells by altering phosphatidylinositol 3-kinase signaling and inducing Zac1 expression. Cancer Res 2006; 66(3): 1576-82.

53. Ferone D, Gatto F, Arvigo M, Resmini E, Boschetti M, Teti $\mathrm{C}$, et al. The clinical-molecular interface of somatostatin, dopamine and their receptors in pituitary pathophysiology. J Mol Endocrinol 2009; 42(5): 36170.

54. Florio T, Montella L, Corsaro A, De Chiara A, Apice $G$, Fazioli $F$, et al. In vitro and in vivo expression of 
somatostatin receptors in intermediate and malignant soft tissue tumors. Anticancer Res 2003; 23(3B): 2465-71.

55. Patel YC, Srikant CB. Somatostatin receptors. Trends Endocrinol Metab 1997; 8(10): 398-405.

56. Reisine T. Somatostatin receptors. Am J Physiol 1995; 269(6 Pt 1): G813-20.

57. Ferone D, Pivonello R, Kwekkeboom DJ, Gatto F, Ameri P, Colao A, et al. Immunohistochemical localization and quantitative expression of somatostatin receptors in normal human spleen and thymus: Implications for the in vivo visualization during somatostatin receptor scintigraphy. J Endocrinol Invest 2012; 35(5): 528-34.

58. Mazzucchelli R, Morichetti D, Scarpelli M, Bono AV, Lopez-Beltran A, Cheng L, et al. Somatostatin receptor subtypes in hormone-refractory (castration-resistant) prostatic carcinoma. Asian J Androl 2011; 13(2): 242-7.

59. Reubi JC, Waser B, Schaer JC, Markwalder R. Somatostatin receptors in human prostate and prostate cancer. J Clin Endocrinol Metab 1995; 80(9): 280614.

60. Kosari F, Munz JM, Savci-Heijink CD, Spiro C, Klee EW, Kube DM, et al. Identification of prognostic biomarkers for prostate cancer. Clin Cancer Res 2008; 14(6): 1734-43.

61. Chi KN, Bjartell A, Dearnaley D, Saad F, Schroder $\mathrm{FH}$, Sternberg C, et al. Castration-resistant prostate cancer: from new pathophysiology to new treatment targets. Eur Urol 2009; 56(4): 594-605.

62. Limonta P, Manea M. Gonadotropin-releasing hormone receptors as molecular therapeutic targets in prostate cancer: Current options and emerging strategies. Cancer Treat Rev 2013.

63. Siegel RA, Tolcsvai L, Rudin M. Partial inhibition of the growth of transplanted dunning rat prostate tumors with the long-acting somatostatin analogue sandostatin (SMS 201-995). Cancer Res 1988; 48(16): 4651-5.

64. Maulard C, Richaud P, Droz JP, Jessueld D, DufourEsquerre F, Housset M. Phase I-II study of the so- matostatin analogue lanreotide in hormone-refractory prostate cancer. Cancer Chemother Pharmacol 1995; 36(3): 259-62.

65. Figg WD, Thibault A, Cooper MR, Reid R, Headlee D, Dawson N, et al. A phase I study of the somatostatin analogue somatuline in patients with metastatic hormone-refractory prostate cancer. Cancer 1995; 75(8): 2159-64.

66. Mitsiades CS, Bogdanos J, Karamanolakis D, Milathianakis C, Dimopoulos T, Koutsilieris M. Randomized controlled clinical trial of a combination of somatostatin analog and dexamethasone plus zoledronate vs. zoledronate in patients with androgen ablation-refractory prostate cancer. Anticancer Res 2006; 26(5B): 3693-700.

67. Ruscica M, Dozio E, Motta M, Magni P. Relevance of the neuropeptide $Y$ system in the biology of cancer progression. Curr Top Med Chem 2007; 7(17): 168291.

68. Koppan M, Nagy A, Schally AV, Arencibia JM, Plonowski A, Halmos G. Targeted cytotoxic analogue of somatostatin AN-238 inhibits growth of androgenindependent Dunning R-3327-AT-1 prostate cancer in rats at nontoxic doses. Cancer Res 1998; 58(18): 4132-7.

69. Lo Nigro C, Maffi M, Fischel JL, Formento P, Milano $\mathrm{G}$, Merlano M. The combination of docetaxel and the somatostatin analogue lanreotide on androgen-independent docetaxel-resistant prostate cancer: experimental data. BJU Int 2008; 102(5): 622-7.

70. Lo Nigro L. Biology of childhood acute lymphoblastic leukemia. J Pediatr Hematol Oncol 2013; 35(4): 245-52.

71. Tang X, Takekoshi S, Itoh J, Umemura S, Shoji S, Terachi $\mathrm{T}$, et al. Somatostatin analogue inhibits the mobility of prostate carcinoma cells: a new therapeutic method for advanced prostate carcinoma. Int $\mathrm{J}$ Oncol 2010; 37(5): 1077-83.

72. Yan L, Xing Z, Guo Z, Fang Z, Jiao W, Guo X, et al. Somatostatin derivative (smsDX) targets cellular metabolism in prostate cancer cells after androgen deprivation therapy. PLoS One 2013; 8(2): e55790. 